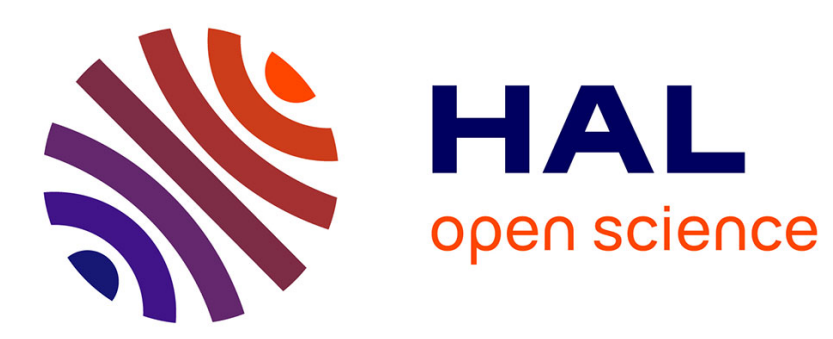

\title{
Service innovation for sustainability: paths for greening through service innovation
}

\author{
Faridah Djellal, Faïz Gallouj
}

\section{To cite this version:}

Faridah Djellal, Faïz Gallouj. Service innovation for sustainability: paths for greening through service innovation. 2015. halshs-01188530

\section{HAL Id: halshs-01188530 \\ https://shs.hal.science/halshs-01188530}

Preprint submitted on 31 Aug 2015

HAL is a multi-disciplinary open access archive for the deposit and dissemination of scientific research documents, whether they are published or not. The documents may come from teaching and research institutions in France or abroad, or from public or private research centers.
L'archive ouverte pluridisciplinaire HAL, est destinée au dépôt et à la diffusion de documents scientifiques de niveau recherche, publiés ou non, émanant des établissements d'enseignement et de recherche français ou étrangers, des laboratoires publics ou privés. 


\title{
Service innovation for sustainability: paths for greening through service innovation
}

\author{
Faridah Djellal and Faïz Gallouj
}

\author{
Clersé, University Lille 1 - Science and Techology
}

\begin{abstract}
:
The purpose of this work is to examine the extent to which services and service innovation can contribute to sustainable development in its environmental dimension. The supposed immateriality of services seems to argue in favour of their natural sustainability. This is actually just a myth - one we examine the roots of, and which we refute. This calling into question of the naturally-green-servicesmyth does not, however, mean that the greening of the economy cannot rely on services. On the contrary, greening also fundamentally depends on innovation dynamics being implemented in or by services.
\end{abstract}

\section{Introduction}

More than two decades of research in economics and managementscience, have helped to make service innovation a relevant, legitimate and increasingly important issue in the field of innovation studies. The (recent) maturity of this field of research is illustrated, to some extent, by the rising number of both qualitative and quantitative literaturereviews covering the topic of innovation in services, in both its general and its specific (sectoral or thematic) aspects. A recent review of these reviews is provided in Gallouj and Djellal (2015).

Research efforts have naturallymainly focused on two (often related) issues, namely the nature of innovation in services, and its production modes. Does innovation in services (in terms of form, how it is produced) differ from innovation in goods? This is the main question that has long guided the emergingfield of service innovation studies. Depending on how this question is answered, the literature considers three analytical perspectives used to address innovation in services: a technologist/industrialist or assimilationist perspective (negative response to the question), ademarcation/differentiation perspective (positive response) and an integration/synthesis perspective (reconciling goods and services, their differences and similarities, within a single analytical model) (Gallouj 2010). A fourth perspective, labelled inversion perspective, focuses on the strategic role played by certain services (KIBS) in the their customers' innovation.

In recent years, innovation studies have been bolstered, in various ways, through the exploration of new themes (e.g. KIBS in innovation, social innovation, public-private innovation networks, public policies for service innovation, etc.) and through empirical investigation in new sectors. They have also been reinforced by complementary qualitative work using quantitative surveys, relying in particular on the revision of OECD Manuals (Oslo 
and Frascati Manuals) as well as on the launch of national surveys(see Community Innovation Surveys in particular).

However, the maturity and legitimacy of service innovation studies also depend on their ability to be in line with the great contemporary socio-economic issues. From this point of view, sustainability isundoubtedly a key issue. Contemporary economies are certainly service economies, and if they are - or truly aspire to be -sustainable development economies, then the question of the relationship between services and sustainable developmenthas to be addressed. However, in spite of certain notable exceptions - such as reporting on the adverse effects of transport and tourism on the environment - little attention has been paid to this question so far.Sustainability is still seen as a predominantly industrial issue (Djellal and Gallouj, 2010, 2015).

The purpose of this chapter is to examine - mainlyfrom a theoretical angleat this stage - to what extent services and service innovation can contribute to sustainability in its environmental dimension (in other words to 'economic greening') -that is, to the satisfying social needs while leaving the smallest possible ecological footprint. Our focus in this work is thus not (or at least not directly) on the economic and social dimensions of sustainability.

Some intrinsic characteristics of services - especially their immateriality - seem to argue in favour of their natural sustainability. This is actuallyno more than a myth ${ }^{1}$ and one we propose, in Section 1 of this chapter, to examine the foundations of, achieving its deconstruction. This calling into question of the myth of 'naturally green' services does not mean that the greening of economic activity(at either micro or macro level) cannot rely on services. On the contrary, in section 2 we show that greening also fundamentally depends on innovation dynamics implemented in or by services.

\section{Servicesare green by nature: the foundations of a myth,and its deconstruction}

The idea that services would be greener and more sustainable, that is, less damaging to the environment than goods, is not uncommon in the literature (Claval, 2006; Illeris, 2007; Rifkin 2000; OECD, 2000; Ellger and Scheiner 1997). It even seems to be confirmed by some statistical analyses at both international and national level.For example, the International Energy Agency (2008) estimatedthat, in 2005, services (excluding the transport sector) accounted for $12 \%$ of $\mathrm{CO}_{2}$ emissions and $9 \%$ of total final energy consumption, worldwide. In the case of France, although the services sector (excluding transport) accounted for almost $75 \%$ of GDP and employment, it was responsible for only $7 \%$ of $\mathrm{CO}_{2}$ emissions in $2008^{2}$ and consumed $15 \%$ of total energy in 2010 (CEREN, 2012).

This idea of the 'natural greenness' of services is based on their immateriality, which is meant to provide a relatively satisfactory criterion with which to distinguish services from goods ( $\S$ 1.1). Because they are supposed to be immaterial, services would, the thinking goes, be less harmful to the environment than material goods - whose manufacturing process gobbles up natural resources and is a source of pollutant emissions, etc. The tertiarization processes at work in contemporary economies should therefore automatically lead us to more

\footnotetext{
${ }^{1}$ It should be noted that this is a positive myth, while the service economy is more verbose in negative myths: for a discussion of these myths, see Gallouj (2002)

2 Data from CITEPA: Centre Interprofessionnel Technique d'Etudes de la Pollution Atmospherique [interprofessional technical center for the study of atmospheric pollution] concerning $\mathrm{CO}_{2}$ emissions, excluding LULUCF (Land Use, Land-Use Change and Forestry).
} 
immaterial/intangible - and therefore more sustainable economies (Ettighoffer 1992; Romm et al., 1999).

This attractive hypothesis is, however, debatable. It is possible, for example, to note that the most tertiarized contemporary economies are also the biggest polluters, and that certain service sectors (transport in all its forms, for example) are among the top sources of negative environmental externalities. Beyond simple fact, our purpose is to reconsider the myth of immaterial and therefore green services, from an analytical angle. Step 1 in this reconsideration process is an attempt to identify a certain number of (forgotten or neglected) sources ofservice materiality (from a static point of view) (§ 1.2).Step 2 isthe highlightingof the socially-constructed (and therefore changing) nature ofservice materiality/immateriality, depending on the output convention adopted $(\S 1.3)$ andStep 3 consideration of the search for materiality as the subject of active strategies carried out by service organizations ( $\S 1.4$ ). Inverse dematerializationstrategies will be considered in the second section of this work, which is exclusively devoted to them.

\subsection{The foundations of the green services myth}

Across the board, from economics to management science, works on services ritually recall a list of technical characteristics that are supposed to be intrinsic to services, namely: Intangibility (immateriality), Heterogeneity, Interactivity and Perishability. This is particularly true in marketing, where the IHIP acronym is common knowledge. These characteristics have long been considered quasi-genetic criteria (a kind of DNA)serving to distinguish services from goods.

This definition of the essence of services by their immateriality is rooted in the history of economic thought, particularly among classical economists (Smith, 1960 [1776]; Say, 1972 $[1803])^{3}$.

He does not explicitly use the term 'immaterial', yet Adam Smith is considered the precursor of the definition of services by their immateriality. This intrinsic technical characteristic of services comes from the distinction Smithmade between 'productive' and 'unproductive' labour. Only productive labour (for example, the labour of the workmanin a factory) creates wealth, because it adds value to the material it processes and it brings about material results, whichare likely to lead to accumulation. In contrast, services ${ }^{4}$ are performed by unproductive labour, that is to say, which "does not fix or realize itself in any permanent subject, or vendible commodity, which endures after that labour is past, or for which an equal quantity of labour could afterwards be procured" (Smith, 1960 [1776]). The immaterial nature of services is often derived (in a way that is perhaps somewhat unsatisfactory) from the idea formulated by Smith (and taken up by Alfred Marshall) that the"work of all [the services] perishes in the very instant of its production" (ibid.). Admittedly with some ambiguity, then,the unproductivity ofservice work (its inability to create wealth) is, in Smith's words, a synonym for immateriality.

Itwas another classical economist, Jean-Baptiste Say (1972 [1803]), whofirstexplicitly introducedthe 'immaterial' qualifier to thedefinition of services. Jean-Baptiste Say called into question the implicit and ambiguous identity established between unproductivity and

\footnotetext{
${ }^{3}$ For a review of the debates on services in economic thought, see Delaunay and Gadrey (1992).

${ }^{4}$ Smith provides a number of examples of service providers including domestic servants, servants of the state, servants of the church, artists, lawyers, doctors...
} 
immateriality (theevanescent nature of the output). According to him, services, while immaterial, are not unproductive, since they are useful,the source of visibleand enduring (accumulative)results (changes) - for example the healing produced by the work of doctors. In Smith's analysis, Gadrey (2000) identifies the premises of a distinction between immediate or direct output on the one hand, andthe mediate output on the other - the outcome or long-term or indirect result ('change of state'in the reality subjected to the services provided). Only the immediate output is evanescent, the outcome itself is lasting: for example health, education and culture havedurable effects on the mind or body. To take another example provided by Smith himself, though the immediate work of the domestic servant may be evanescent, the resulting cleanliness does not vanish once the work is done, butendures some time.

The reasoning which, in modern economies, involves translating this genotype (that is, these technical characteristics) into an environmentally-friendly phenotype is obvious. Since the output of services is immaterial, evanescent and transient, it is supposed not to harm the natural world, unlike industrial and agricultural production which transforms raw materials into physical goods, damaging the environment in both their production and their consumption. Such reasoning is clearly mistaken. Services are both less immaterial,and less green than they seem - it all depends on how the materiality issue is addressed. Services are of course immaterial in the sense that they are not intended to produce tangible goods as final output. However, their relationships with materiality may take a range of forms, in line with the types of services envisaged. In the following paragraphs, we examine these different relationships.

\subsection{The (neglected) sources of service materiality}

Given the link established between the level of materiality and the sustainability of services, in calling into question the principle of intrinsic immateriality of services (genotype), we also query its supposed positive effects in terms of sustainability (phenotype). We therefore propose, in this paragraph, to seek to identify neglected sources of servicematerialitywhich undermine the myth of its natural sustainability.

Service materiality maymanifest itself in different places: (a) in the service medium or target; (b) in variousestate facilities, that is the physical spaces of production/consumption; (c) in the production factorsdeployed in the service relationship. While it is important not to neglect the (physiological) materiality of the human factor, it is of course on the capital factor that we focus here. A further significant source of (direct and indirect) materiality stems from another intrinsic characteristic attributed to the service - its interactivity, its coproduced character (d). Indeed, interactivity is often associated with mobility, which requires implementation of a certain number of transport facilities and infrastructure- these being highly material and damaging to the environment.

\section{a) Materiality of the service medium}

The diversity of services in their relationship to materiality is obvious. Even intuitively, it escapes no-one that transportation, waste processing, cleaning, catering, hostelry, and car repairs are more 'material'services than are consultancy, training, insurance or psychotherapy. Even within the confines of these few examples alone, we might add that nothing is more material than the dishes prepared in a restaurant's kitchen, whereas psychotherapy is primarily a verbal exchange. 
Beyond plain intuition, by mobilizing theoretical works devoted to definition of the service concept (Hill, 1977; Gadrey, 2000), this difference in materiality betweenservices can be interpreted by the difference in materiality between their mediums. Indeed, drawing on Hill, Gadrey (2000) defines the service as a "set of processing operations seeking to change the state of the service medium". Theservice medium is in turndefined by the target or reality modified or worked upon by the service provider on the customer's behalf.It may take different, more or less material forms: (i) a material good,(ii) codified information, (iii) individuals (customers, users) themselves having physical, intellectual or locational characteristics, and iv) organizations, again in their various aspects (technologies, structures, collective competences and knowledge).

The 'change of state'effected by the service can be considered immaterial (healing for the sick, satiety for the guest of a restaurant, repairsto a car, improvedcultural awareness, knowledge and employability for a student). Such a change of state canneither bestorednor surrendered, regardless of the medium to which it is consubstantially linked. The service medium may, however, be more or less material, leading to the serviceitself in turn being considered more or less material.

The degree of materiality of the medium is the basis for a number of service typologies. Thus-when focusingon the difficulty of defining and measuring productivity in servicesGadrey (1996) has proposed a typologywhich canbe extrapolated without difficulty to the services sustainability issue. This typologyincludesthree groupsof services whosedifferencesare markedby their mainmedium:

1) Services that mainly involve the physical processing of technical mediums. These differ little from the conventional production of physical goods, which is the category to which the statistical conventions would in any case have assigned them (passenger and goods transportation, repair of goods, catering, hostelry,retailing, various rentals, standardized processing of codified information (e.g. some functions of banks and insurance companies...). 2) Intellectual services applied to organized productive knowledge - often referred to as 'intangible' or 'pure' services because, unlike those of the previous group, these services are not primarily focused on goods (engineering, consultancy services, R\&D, software production, advertising/PR services, etc.).

3) Services applied to individuals' knowledge and capabilities, in finalconsumption, and posing significant problems with regard to the identification and measurement of output (education, health, leisure, culture, etc.).

In the previous typology, the service is defined by the main mediumthat is the subject of the 'state change process'. This means that in reality every service activity operates, to varying degrees, on several mediums, so that every service activity is in fact a combination of functions associated with these different mediums (material, informational, cognitive, relational, etc.). These combinations varyacross space, and especially over time (we will return to this issue in point 2.1a).

\section{b) The materiality of service production/consumption spaces}

Another key expression in the materiality of services is the materiality of their production/consumption spaces. The service economy is often associated with the absence of factories and heavy-duty production lines. However, services do also require production/consumption spaces such as offices, classrooms, hospitals, railway stations, and 
airports. It would clearly be wrong to conclude that these spaces are environmentally benign one has only to consider the space taken up by such service facilitiesas supermarkets, airports, logistics platforms, university campuses, hospitals, landfills, etc. The environmental damage attributable to these production/consumption spaces manifests itself in a variety of ways: use of space, energy consumption, waste generation, emissions, noise, visual and olfactory disturbances, etc.

From an organizational perspective, the question of the production space materiality is often considered via making a distinction between two different spaces: the back office and the front office. The back office is where the material or informational transformations of service mediumstake place in the absence of the customer (for example, the restaurant kitchen or the various departments within a company). The front officeis the customer-facing area (for example, thefloor of a restaurant, the bank counter or the hotel lobby).

In management science, and in marketing in particularly, an extensive literature has developed in recent years, seeking to take full advantage of these production/consumptionspaces and enhance their materiality. This aspect of materialization strategies will be discussed in paragraph 1.4.

\section{c) Materiality of the production factors deployed}

Even though the labour factor has an evident physical existence,here we are addressing the issue of capital materiality. The third sector theory is built upon the idea that services are lowcapital-intensive, and primarily based on the mobilization of labour. Colin Clark, a founding father of the theory of the third sector, observes that"most service businesses require far less in the way of capital goods than industry or agriculture"(Clark,1940). This low capital- intensity lies at the heart of the first positive (rather than residual) definition of the tertiary sector. According to Fourastié (1949), the service sector includes activities for which productivity growth rate is low due to weak mechanization. Baumol (1967) relies on the same assumption in his unbalanced growth model which defines services as a stagnant sector, wherasgoods belong to a progressive sector.It should however be noted that in a later work, Baumol et al. (1985) qualified this analysis by introducing an asymptotically stagnant sector combininga progressive and a stagnant component. An example of this is provided by the IT sector, whose hybrid nature(hardware + software), starts out progressive, while the hardware element is proportionately dominant, then evolves towards stagnation as the software component grows stronger.

This negative assessment of the capital-intensity (and materiality) of the services (and conversely, the positive assessment of their sustainability) must be qualified and called into question- both staticallyand dynamically. First of all, it is undeniably true that some services have long been characterized by their high capital-intensity: this isthe casenot only of transport in all its forms (passenger and goods transport, air, rail, land and sea transport, etc.), but also of energy and water supply activities (public utilities) for which the question of theirbelonging to 'industry' or 'services'continues to be a matter of debate (Broussole, 2014). Yet it is clear, from a dynamic perspective, that services are increasingly capital-intensive. They fall within the scope of natural technological trajectories in the sense of the evolutionary theory (Nelson and Winter, 1982), i.e. trajectories of increasing mechanization. We will return to this point in paragraph 1.4.

\section{d) The material dimensions of interactivity}


Interactivity is another essential (intrinsic) technical characteristicof services. It refers to the different forms of interaction between service consumer and service producer(different modalities of the service relationship), which reflect various levels of co-production of the serviceby the consumer. Like immateriality, this technical characteristic of services also has its roots in the history of economic thought. Storch (1823) is often cited as its precursor.

This service interactivity is also a source of materiality - and therefore of adverse effects to the environment. It often presupposes a physical encounter, which entails travelling on the part of service relationship protagonists. These journeys are material-intensive because they mobilizenot only transport infrastructure and technical systems, but also differentencountervenues, depending on the nature of the mobilityin question. Interactivity thus has an effect on materiality, especially through the twoabove-mentioned vectorsof materiality (see $\S b$ and $c$ ) - namely the factors of production and production/consumption spaces.

Several types of journeyscan be distinguished (Gadrey, 2010; Fourcroy et al., 2015):(i) journeysby consumers or users to the place of service production/consumption (for example, in trade, catering, hostelry, education or health, at least in their traditional dominant form); (ii) journeys by service providers to the customer, be this a firm or a end consumer (e.g., consultancy, certain sales formulas, home services); (iii) simultaneous journeysbyservice providers and clients (passenger transportation in all its forms); (iv) journeysmade byservice organization employees to their workplace.

These different types of journeys involve individuals whose mobility is required for theestablishmentof the service relationship, that is the encounterbetween client and provider. The mobility can however also concernmaterial goods: material inputs required to produce the service, as well as the goods that are the subject of the service transaction (e.g. supply to stores in retailing, delivery of goods to customers in mail-order selling).

Service-associated journeys are a major source of energy consumption. In 2007, in France, they represent approximately $40 \%$ of official tertiary sector energy consumption (Fourcroy et al., 2012). The scale of these journeys and their impact on sustainability are such that Gadrey (2010) has no hesitation in predicting the decline - and even the demise - of whole swathes of thetertiary sector, unlessappropriate solutions (innovations) are found. Examples of suchactivities are transportation and all services relying heavily on transportation - including international tourism and business travel, hostelry, postal services, etc.

\subsection{A materiality/immaterialitythat dependson the output convention adopted}

Immateriality is not an (objective) intrinsic technical characteristicof services, just as materiality is not anymore always seen as a fundamental dimension of goods (see $\S 2.2$ ). The degree of materiality is a social construction, which depends on the output conventionsadopted. The materiality of the service and its impact on the environment differs, depending on the delineation of the border of the service, according to its topographical and temporal coordinates.

In the following paragraphs, we consider the output convention at three different levels:

- the technical (topographic) delimitation ofthe boundaries of the service activity as such (this level essentially reflectsthe direct materiality of the service); 
- the focus on the indirect dimensions of the materiality of the service, particularly (but not exclusively) from a time perspective, involving an analysis in terms of life cycle;

- thefocus on the universal nature of the "service provided" as an ontological characteristic of both services and goods.

\section{a) The physical scope of the service}

It is obvious that, depending on the border that is drawn to delimitate the service, the level of its materiality and therefore of its sustainability can vary considerably. Thisrelationship between the output convention adopted and sustainability can be illustrated in the case of the evaluation of energy consumption. Such an exercise was performed by Fourcroy et al. (2012), who propose to break down the service into three components (basic services), which give rise to different energy needs (see Figure 1): conditioning, service operations and travel.

According to the definitions of the service previously mentioned ( $\S 1.2 \mathrm{a})$, service operations consist in the mobilization of competences and techniques in order to make transformations on the various mediums of the service (material object, information, knowledge, the individual). These operations require technologies, particularly technologies for material and information processing, which are energy consuming.Conditioningrefers tothe whole set of energy-consuming activities achieved for thepreparation of the physical space of the service activity(fitting out, cleaning, heating, air conditioning, lighting, etc.).These activities take place upstream of the service operations, but also during the operations and partly after them.Travel refers of course to the different configurations of the journeys made by the service protagonists before, during or after the service operations (see section 1.2d). It is a major source of energy consumption and pollution. It should be noted that conditioning activities and service operationscould take place in the premises of the company or outside the company.

\section{Figure 1.The Scope of Energy Consumption in the tertiary sector as assumed in CEREN} statistics (source: Fourcroy et al. 2012)

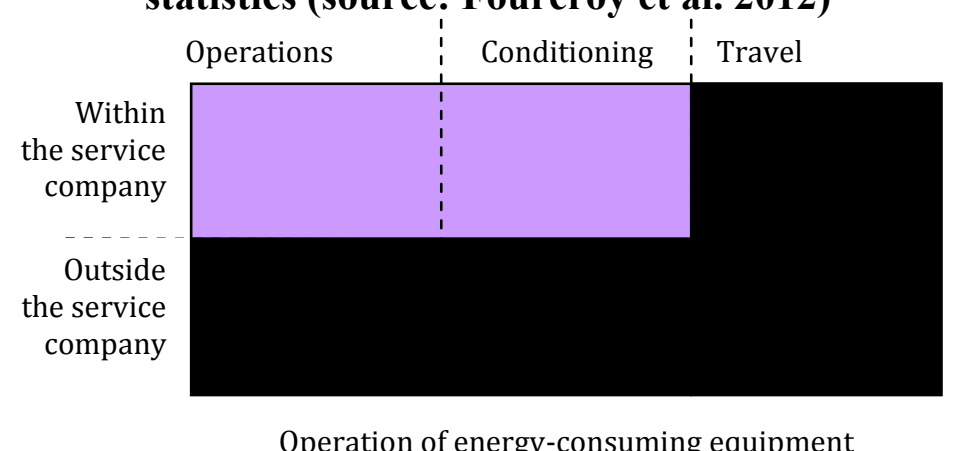

Key:

Consumption excluded in the CEREN energy statistics

However, the official energy statistics (for example, in France those of CEREN ${ }^{5}$ ) limit the scope of energy consumption to conditioning activities and service operationswithin the service firm. The only energy consumption taken into account are those of theequipment used

\footnotetext{
${ }^{5}$ CEREN: Centre d'Etude et de Recherches Economiques sur l'Energie [Centre for study and research into energy economics]. This is the major French organization supplying energy statistics on the tertiary sector.
} 
within the premises of the service organizations. Therefore, the measurement conventions underestimate the energy consumption and more generally the negative environmental externalities in the tertiary sector. They exclude, in fact, on the one hand, the energy consumption of conditioning activities and of service operationsperformed outside the service firm, and on the other hand, the consumption related to travel activities.

By adding to the official statistics, the energy consumption generated by the whole set of journeysrelated to the consumption or production of services (journeys the service consumers in order to consume the service, journeys by service organizations employees from home to their workplace, journeys by service providers for professional reasons), Fourcroy et al. (2012) estimate, in the case of France, and for 2007, that the energy consumption is multiplied by a factor of 1.4 .

\section{b) The direct and indirect sources of materiality}

The discussion of the materiality of services (and of its negative effects in terms of sustainability) is often restricted to its direct sources. But there are also indirect sources of materiality. Taking them into consideration would contribute toscale up the adverse environmental effects of services.

Direct sources of materiality (and corresponding negative externalities) are those which appear immediately within a given service provision. They reflect the negative externalities directly generated by the use of the different material elements (service medium, production factors, production/consumption spaces, etc.), within the different component of a service (operations, conditioning, travels).

Indirect sources of materiality, for their part,are those that are induced by the service in question in the rest of the economy and/or at other times, upstream or downstream the service. There are (at least) two different types of indirect sources of materiality (Fourcroy et al., 2012).

The first type can be addressed by an analysis in terms of life cycle, applicable to the whole set of material goods mobilized during the service provision: technical equipment of course, but also buildings, furnishings, intermediate consumption of various goods, goods sold (e.g. in retailing). These different material goods are not only sources of materiality (and externalities) during their use (direct materiality previously mentioned), but also, upstream, at the moment of their own design, production andselling, and downstream, when they are maintained or repaired and possibly recycled at the end of their life. By analogy with grey energy, thisincorporated materiality can be labelled "grey materiality".

The second type of indirect source of materiality of the service corresponds to the materiality associated with the different types of intermediary services, necessary for the provision of the final service in question. These may include, for example, cleaning services, catering services, consultancy services. These intermediary services also, recursively,involve direct and indirect sources of materiality. The former correspond to the negative externalities that appear immediately during the delivery of the intermediary services in question and which are generated by the different vectors of materiality of these intermediary services (equipment, furnishings, buildings, etc.). The latter correspond to the grey materiality of these intermediary services themselves and, recursively, to the materiality of the intermediate services necessary for the provision of these intermediate services themselves, etc. 
Figure 2 provides an illustration of the distinction between direct and indirect sources of materiality, in the sole case of energy consumption. It can easily be generalized to all direct and indirect sources of materiality. Using an input-output method, Fourcroy et al. (2015) estimate that in France, for 2009, taking into account grey energy multiplies the energy consumption in services by a factor of 1.6 (it is even doubled in certain service sectors such as the information and communications sector).

Figure 2 The total direct and indirect sources of energy consumption in a final service

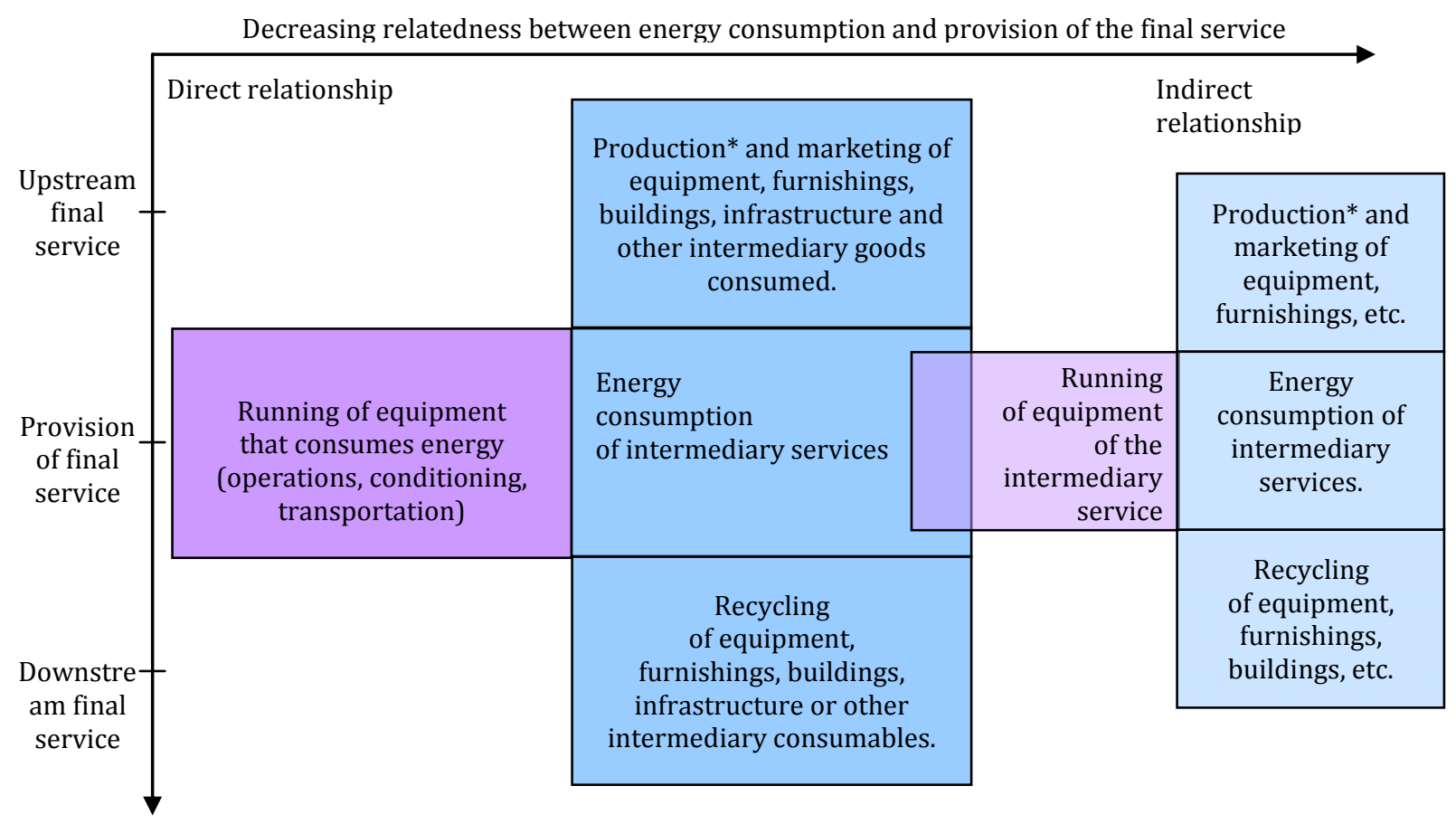

Grey energy of equipment, furniture \& furnishings, buildings, infrastructure, etc.

*Production in the broad sense.This includes:the design of the project, the extraction and transportation of the necessary raw materials, the processing of raw materials and fabrication of the product.

\section{c) The service as a common ontological characteristic of both goods and services}

The idea of the subjective and conventional nature of the border of services (of the difference between goods and services) probably culminates in the recent theoretical work, which consider that the search for specificity (materiality of goods vs. immateriality of services) is counter-productive, since in fact "everything is service".

These works share the idea of a certain (observed or desired) blurring of the boundaries between goods and services and the need for common theoretical models. They actually rediscover the principles of consumer microeconomics: the utility, the value in use, the service or final characteristic as an ontological characteristic of both goods and services. This common immaterial nature of goods and services, which militates in favour of integrative or unifying theoretical analyses, is at the heart of all the following theoretical constructs: the functional economy theory(Stahel, 1997; Du Tertre, 2007; Boutillier et al. 2014), which defines anyoutput (goods or services) by the function (service) it provides, the experience economy theory (Pine and Gilmore, 1999), which defines the outputby the experience it provides to the consumer, the "Service-Dominant Logic" (SDL) (Vargo and Lusch, 2006) 
whichdefines the value by the value in use, therefore erasing the difference between goods and services, and the "Service science" (Maglio and Spohrer, 2008) which is a science of both goods and services. Another formulation of this integrative theoretical perspective is more directly focused on the innovation issue. This is the approach (of the product and of innovation) in terms of characteristics developed by Gallouj and Weinstein (1997) and extended by a number of other works (De Vries, 2006; Garcia-Goñi and Windrum 2008; Gallouj and Toivonen, 2011, etc.).

However, if they share a common desire of theoretical synthesis, these integrative theories do not pursue the same key objectives. Thus, the main initial project of the functional economy theory (Stahel, 1997) is to develop a theory of sustainable development. Therefore environmental issues occupy a central place in this theory. The analysis in terms of SDL (Vargo and Lusch, 2006) and the experience economy theory (Pine and Gilmore, 1999) essentially fall into the scope of a perspective of service marketing. They rediscover and operationalize the use value, and the new consumer economics (Lancaster). The approach in terms of characteristics (Gallouj and Weinstein, 1997) is also of Lancasterian inspiration. Its main purpose is to provide a theoretical model that accounts for the diversity of the innovation dynamics in both services and goods. But of course, these theories can add (or have already added) to their research agenda, purposes other than their original purpose. Thus, for example the functional economy theory and SDL are increasingly addressing innovation issues (Ordanini and Parasuraman, 2011; Vargo et al., 2014). The approach in terms of service characteristics strives to integrate environmental and more generally sustainability issues (Djellal Gallouj, 2015; Cruz et al, 2015).

\subsection{The rise in materiality as an active strategy of service organizations}

In management sciences, real or supposed immateriality of services has long been regarded as a weakness to be corrected. This immateriality of the service and its associated heterogeneity/variability character, are the origin of performance evaluation issues (service quality, cost or labour productivity) concerning both the client and the service provider (Gadrey 1996; Djellal and Gallouj 2008a). Therefore different (innovation) strategies have been implemented to introduce material elements in services or optimize existing ones. Some authors (especially Levitt, 1972) established this rise in materiality as a strategic imperative for service organizations, advocating for a systematic "industrialization" of services.

The increase in material intensity of services and their industrialization can take different forms that are closely related, but that we present separately, in order to highlight the different materialization (and industrialization) mechanisms at work.

The first form of materiality rise is the introduction of material technical systems in service companies and organizations. The information and communications technologies that spread invasively in services are (especially in their hardware dimension) an essential source of this materialization process. But other technologies also play a key role (often by hybridization with ICTs): cooking, cooling and ventilation technologies, transportation technologies, medical technologies, etc. As highlighted by a certain number of works (Berkhout and Hertin 2001; Faucheux et al., 2002; Gadrey, 2010), these technical systems are intensive consumersof exhaustible natural resources (rare metals) and energy. They also raise formidable problems related to the treatment of waste. Their development is often artificially supported by extremely short life cycles associated with quasi-programmed obsolescence (Desmarchelier et al., 2011). 
The second form of materiality rise is, paradoxically, the implementation of what may be called soft or "immaterial" technologies. This is the standardization of work processes, the implementation of industrial production methods, models, blueprints (Levitt, 1972; Lovelock, 1992; Kingman-Brundage, 1992), which are veritableproduction "manuals" of the service. These invisible technologies lead to a standardization of the service itself. The product, in this case, is not a good, but a quasi-product: for example, a standard insurance contract or a standard financial product, a tourist standard package, a standard menu item identical throughout a fast food chain (McDonald's is often cited as the archetype of the industrialization of catering). Industrialization means, then, eliminating cases that are not standard cases.

The third form of materiality riseinvolves the physical spaces of production/consumption of the service. It can be addressed in two different ways. The first reflects the development, inpossibly innovative forms of these spaces defined as architectural entities (external or 'property'materiality). The icons of this property materiality are large shopping centres, logistics platforms, transportation hubs, etc. It should be noted that this property materiality can even, in certain cases, rely on industrial production processes, since some modules of the building infrastructure are pre-fabricated in a factory (this is the case, for example, of Hotel Formule 1 of Accor Group). The second way to address the rise of materiality of the physical spaces is to look at the materiality that manifests itself within the infrastructures. This internal materiality is critical to customers, who are sensitive to the aesthetic and functional qualities of the internal architecture and of the furnishings: accessibility to spaces, signage, appearance, decor, comfort, ergonomics, etc. All these elementscontribute to make tangible the immaterial and the heterogeneous, and are the subject of intense innovation efforts. The strategies implemented to optimize the internal materiality may have different but complementary goals: communication/advertising, improving access and mobility, optimizingthe clientprovider interaction, reducing uncertainty about the quality, etc.

The last form of materiality rise that we evoke does not concern the production but the consumption sphere. It manifests itself by the rise of the self-service in Gershuny's meaning (1978), that is to say the replacement of services by industrial goods used at home: for example, the replacement of the laundry service by the use of one's own washing machine, the replacement of the cinema bythe DVD at home, etc.

\section{Greening the economyby innovation in services and $b y$ services}

In the first part of this work, we have argued that, contrary to an old assumption, the service is not green and sustainable by nature, but that it includes direct and indirect sources of materiality, which serve to increase its ecological footprint. We have raised the innovation issue only in addressing these sources of materiality in dynamic terms, that is to say by focusing on the materialization/industrialization strategies implemented in service companies and organizations.

In this second part, we address innovation from a different angle, that of dematerialization strategies. In a service economy, innovation in services and by services plays a key role in the process of dematerialization and greening. This greening of the economy by services and service innovation can take two different but complementary paths: first, the greening of the services themselves through the implementationof dematerialization strategies and green 
innovations trajectories within services sectors $(\S 2.1)$; then, the greening of goods by services and services innovation $(\S 2.2)$.

\subsection{The greening of services themselves: the green innovation trajectories in services}

We consider here how, through appropriate innovations strategies, services can dematerialize and green themselves. To account for these internal or endogenous dematerialization strategies, we rely on the different dimensions of the materiality of the service previously considered, namely the materiality of(i) the service medium, (ii) the production/consumption spaces and (iii)the production factors. We will not discuss here separately dematerialization strategies associated with the interactivity of the service, to the extent that they are actually special cases of dematerialization strategies related to production factors (transport systems) and production and encounter spaces. This analytical approach is simplifying since the different materiality sources separately addressed here are interdependent in reality.

\section{a) Dematerializationand greening of the service medium}

Aswe mentionedin paragraph 1.2, the medium of the service can take different more or less material forms: a (material)good, the individual himself,codified information, knowledge. If, in theory, a service activitymay be defined bythe nature of itsmain medium(therefore several types of services aredistinguished:material, informational, cognitive, relational services...), a service organizationis mostlyprocessing simultaneouslythese variousmediums, combined invarying proportions. Thesecombinations are notstatic butdynamic, andin particular, theymay evolveaccordingto dematerializationtrajectories.

Depending ofthe analytical level adopted(macro, meso, micro), the dematerialization of services, considered in termsofthe dematerialization of theirmediums,canbe interpretedin different ways.

At the macro or mesoeconomic level, the dematerialization of the medium may manifest itself by a rise of informational, cognitive and relational services at the expense of material services. This structural changeis reflected by concepts such as 'information economy' or 'knowledge economy'. It is also at the heart of the post-industrial society as defined by Daniel Bell (1973), namely, a society that is moving towards the higher-level services in which the mediums of service provision are human beings and knowledge (in particular health, culture, leisure, research and public administration)to the detriment of so-called lower-level services characterized by the processing of tangible goods(transport, retailing, etc.).

At the micro level, this dematerialization is expressed by the rise, withina given organization (or activity), of processing operations of immaterial mediums (information, knowledge and relationship with the individual) to the detriment of processing operationsof physical mediums. The outsourcing of certain material services activities (e.g., catering, transportation, cleaning) can contribute to this process of dematerialization. However, as highlighted by Djellal and Gallouj (2008b), the various mediumsof the service and the various corresponding functions (operations) can be associated with different technology families: materialprocessing technologies (robotics, mechanics,...), information processing technologies (IT, telecommunications), knowledge processing technologies (soft technologies, methods...). Thus, in a given activity (or service organization), the rise of the immaterial mediums and functions with respect to material mediums and functions is bound by a reciprocal causality to the change of relative weights of technological families and corresponding innovations 
trajectories. The dematerialization of the service is thus associated with the rise ofimmaterial innovation trajectories (pure service, cognitive (methodological) and informational (in its software dimension)at the expense of material innovation trajectories (see section c).

\section{b) Dematerialization and greeningof production/consumptionspaces}

The dematerialization and greening process of production/consumption spaces fall into the scope of two distinct groups, which are not fully independent. The first group includes the different operating modalities of the dematerialization and greening of traditional production/consumption spaces, while the second group consists of "alternative spaces" to these traditional spaces.

In the first group, dematerialization and greening of the traditional production/consumption spaces can be operated in different ways, which, essentially, referto building engineering and architecture (including interior architecture). Thus dematerialization and greening cover, first of all, innovation efforts to build sustainable property infrastructure (ecoconstruction, HQE approach) whether these efforts focus on the nature of the materials used, the nonintrusiveinclusion of infrastructure (the buildings) in the natural environment or the configuration of interior spaces, etc. They also cover, in somerespects ${ }^{6}$, "architectural and spatial" facets of the so-called low-cost or service regression strategies(Djellal and Gallouj, $2005,2008 b$ ). Indeed, these service regression strategies simplify not only the service offer (by limiting itto the central service and eliminating peripheral services), but also the physical environment of this offer. They are less demanding in volume and quality of reception areas (see, for example, the frugalreception areas of low-cost airlines companies at airports, the Spartan material organization of shelf spaces in discount retail chains) and, according to Fourcroy (2015), less energy consuming. Dematerialization and greening of traditional production/consumptionspaces finally also covers the experience of "smart buildings", reflecting a hybridization of real estate techniques and information technologies (see following item c).

In the second group, dematerialization and greening of production/consumption spaces are obtained by the introduction of spaces, alternative totraditional production/consumption spaces. Some of these alternative spaces are not new, but they are experiencing a significant development. These include, for example, alternative spaces associated with the following services: 1) home services (e.g., home care services, especially elderly care); 2) remote services relying onpost mail, telephone, but especially Internet; 3) services in shared space (e.g. village shop that provides postal services). These alternative spaces can contribute, in varying proportions, and all things being equal, not only to reduce the production/consumption spacesbut also the amount of travel.

\section{c) Dematerialization and greening of the production factors}

The process of dematerialization/greeningproduction factors (limited here to technical systems) can be addressed by focusing on the different ways that innovation trajectories at work in service organizations may evolve: (i) the rise of immaterial innovation trajectories at the expense of material trajectories; (ii) the strengthening of the immaterial dimension within a given innovation trajectory; (iii) the hybridization of several trajectories. The process of the

\footnotetext{
${ }^{6}$ In other respects, and primarily, regression strategies aim more, as we have already stated (see $\S 1.4$ ) to industrialize the service, to make it less intangible, less interactive.
} 
dematerialization of production factors can also be addressed (iv) through changes in material goods ownership and use regimes.

\section{Changing relative weight of innovation trajectories in favour of immaterial trajectories}

First, within a given service company or service activity, the dematerialization/greening process can be considered (as we have already pointed out above)to be a rise in immaterial innovations and technologies at the expense of material innovations and technologies, alongside the rise of the intangible components of the service provision, which is at the expense of its tangible components. In other words, material innovation trajectories reflecting technological developments relating to the transport and transformation of material substances, whether human or physical ${ }^{7}$,become less important than immaterial innovation trajectories which reflect, on the one hand, the production and evolution of formalized methods of knowledge processing ${ }^{8}$ and, on the other, the implementation and evolution of 'pure' services innovation, independent of any technical medium.

\section{Strengthening of the immaterial/green dimension within a single innovation trajectory}

The dematerialization process may also be considered at the level of any one component of the service (material, informational, cognitive, or relational) or at the level of the corresponding innovation trajectory, whether material or immaterial. The idea here is that the innovation trajectories, whatever form they take (material or immaterial), are becoming more environmentally-friendly, meaning that efforts are being made to develop and adopt cleaner, more energy-efficient technologies. For example, within the logistics material innovation trajectory, efforts are made in favour of cleaner transport technologies (electric and hybrid vehicles). Within the material and information innovation trajectories, efforts are also made to reduce the volume (materiality) of new technical systems, so that they are more compact. This trend towards miniaturization and integration is not, however, new. Though evolutionary economics (Foray and Zuscovitch, 1988) has described it as a specific natural technological trajectory insofar as it characterizes the technological evolution of a particular sector (electronics), it is tending to becomea generic natural technological trajectory (concerning many sectors). In the specific case of the informational trajectorydescribing the dynamics of information systems, it is generally assumed that (immaterial) 'software' dimensions tend to outweigh the (material)' hardware'dimensions as the trajectory evolves. Acceptance of this hypothesis thus means that the informational trajectory will evolve in line with a growingdematerialization process. It is on the basis of this hypothesis that Baumol et al. (1985) introduced an asymptotically stagnant sector in the so-called unbalanced growth model.

\section{Hybridization of material and immaterial innovation trajectories}

Dematerialization and greening can also happenthrough the hybridization of innovation trajectories. In the most common case - the hybridization of material and informational innovation trajectories - the question arises as to whether hybridization helps reduce the level of materiality of the new hybrid technical systems formed (to which the answer is probably yes, assuming that the software dimension overrides the hardware dimension). However, beyond this hypothetical dematerialization, there is no doubt that some hybridization strategies, all other things being equal, do have a greening effect: this is the case where the introduction of ICTshelpsstreamline use of a technical system with a view to sustainability and in particular to energy-saving (smart grid solutions) (Hyytinen and Toivonen, 2015). This

\footnotetext{
${ }^{7}$ For example, passenger or goods transportation systems, cooking and refrigeration systems, cleaning systems, various kinds of dispensing machines, visitor attractions, bio-medical or bio-pharmacological innovations, etc.

${ }^{8}$ For example, new consultancy methodologies, new health or cleaning protocols.
} 
is also the case where ICTs are used to carry out service transactionwithout travel (e.g. remote surgery). Conversely, it should be noted that the hybridization of immaterial (pure service and methodological) innovation trajectories and informational innovation trajectories-that is, the introduction of ICTsto bothpure service and methodological innovations, contributes to the pro-materialization dynamic in services(see $\S 1.4$ ).

\section{Changes in production factor ownership anduse regimes}

Dematerialization of production factors (and more generally of material goods) may be achieved through changes in ownership and useregimes. Within the sphere of production, as in that of consumption, individual ownership and private use may give way to different service consumption patterns that do not include ownership (or do not include exclusive ownership) of the goods: leasing, renting, sharing, pooling (see also $\S 2.2 \mathrm{c}$ below). Examples include car sharing (such as BlaBlaCar), shared use of certain sophisticated and expensive technologies, possibly within the context of public-private partnerships (e.g. scanners in hospitals), etc. This fall in materiality, voluntary though it may be, can also be fortuitous, a joint by-product of the pursuit of other objectives. This is, for example, the case of the pooling of heavy equipment in hospitals, which primarily pursues an economic objective.

\subsection{Dematerialization/greening of goods (and of the whole economy)through services}

As we noted in the previous paragraph, services (as activities or organizations) may themselves be subject to dematerialization and greening dynamics. Here we look at another relationship between services and greening, namely the potential role these activitiesmay play in the greening of other economic activities than their own. These greening (dematerialization) strategies can be described as external or exogenous. Within the framework of the so-called economy of functionality, and withina servitization perspective (Vandermerwe and Rada, 1988), the concept of Product-Service System (PSS) (for a literature survey, see Goedkoop et al., 1999; Mount, 2002; Tischner et al., 2002; Tukker, 2004; Baines et al., 2007; Beuren et al, 2013) occupies an important place in this issue ofthe greening by (rather than of) services. Although it is becoming catch-alland ambiguous as it seeks to gain theoretical consistency, this concept has undeniable heuristic value. Indeed, the concept of PSS(initial, pared-down definition: a combined offering of goods and services) has extended to cover more abstract content, and in particular the idea that everything is service.

In this section, we begin by discussing the analytical ambiguities introduced by enriching the concept of PSS $(\S$ a). We then examine the implications in terms of the dematerialization/greening of different PSS formulations, distinguishing two cases: (i) Product-oriented PSS and dematerialization through the addition of services to products $(\S b)$; (ii) Use-oriented PSS and dematerialization through the substitution of services for products (§c).

\section{a)Different PSS concepts, and some ambiguities}

Strictly speaking, Product-Service Systemcan be defined as the association (the joint supply) of products and services to meet consumer needs. Such systems existed long before the concept of PSS was explicitly introduced. Although other denominations reflecting the same idea (the combination of products and services to meet consumer needs) preceded PSS, these have been less successful (Bryson 2010). Examples include 'goods-services complexes' (Barcet, 1987) and 'compacks'- a neologism (from 'complex packages') coined by Bressand, 
1986, (see also Bressand et al., 1989),comprising 'bundles of services and manufactured inputs'.

In the literature, the 'mechanical' definition of PSSsoon gave way to a more complex definition, going beyond thecombination of products and services to include utility and environmental issues. Thus, according to Manzini and Vezzoli (2002), "the concept of PSS promotes a focus shift from selling just products to selling the utility, through a mix of products and services while fulfilling the same client demands with less environmental impact".

On the whole, in recent literature, the PSSconcept seems to be a heterogeneous category, coveringvarious modalities of the (real, theoretical or even rhetorical ${ }^{9}$ ) integration of products and services. These modalities are described in the following terms (Mont, 2002; Tukker, 2004; Bryson 2010 Vandermerve and Rada, 1998 Boutillier et al., 2014): the association of physical products with intangible services; the definition of the product by the services it renders; the sale of the use of a product rather than the product itself (leasing, renting); the sharing or poolingof the use of a product, and repair rather than disposal. Such a broad and open definition of PSS introduces an ambiguity related to the confusion between the service as an activity (as opposed to a product) and the service as utility or use in the sense of economic theory. A PSS connects products and services. But the ambiguity arises, on the one hand,out of the semantic shift thatcharacterizes the term'service', and on the other, out of the nature of the relationship which causes a system to exist.

In an attempt to formally summarize these semantic ambiguities, Let's call $\mathrm{P}$ the product, $\mathrm{S}$ the service, $s$ the final characteristic (utility, use value, service characteristic), $\sigma$ the general (generic) function attributed to a product, a service or a combination of products-services, $\Sigma$ the service uses that can be made of the product $P$.

In contemporary literature, as we have just stressed, the PSS concept now, in an ambiguous and catch-all way encompasses a broad set of relationships (which are not always systemic), associating a product $(\mathrm{P})$ and an expression of the service from among those just mentioned $(\mathrm{S}, \mathrm{s}, \sigma, \Sigma)$. The main relationships in question areas follows:

- P $+\mathrm{S}$. This is the PSS in the strict sense, combining tangible products with intangible services.

- $\Sigma(\mathrm{P})$, which expresses the service uses of a product. These service uses include leasing, renting, sharing, pooling, etc. While a relationshipbetween $\Sigma$ and P does exist here, it can only be called a PSSviaerroneous use of language.

- P $(\sigma)$ or S $(\sigma)$, which formalize the idea that a product or service is defined by the general function it performs: mobility, leisure, health, or education, for example. The relationship between $\mathrm{P}$ and $\sigma$ and $\mathrm{S}$ and $\sigma$ is not itself systemic. In reality a system exists only when $\mathrm{P}$ and $S$ are combined to satisfy a function, which can be formalized as follows: $(P+S)(\sigma)$.

- P (s) or S (s), which, in the Lancasterian tradition, reflect the idea that anyproduct and service is defined by the service characteristics it provides. As in the previous case, the general idea is that products (like services) are defined by the service provided. The difference lies in the fact that the service is not approached in general terms (as a function), but rather broken down into more specific basic service characteristics (e.g. the transport or mobility function is replaced by a vector ofservice characteristics: speed, security, comfort, etc.). Both approaches to the relationship between products and services can have critical

\footnotetext{
${ }^{9}$ This is sometimes a marketing discourse
} 
implications on both perception of the level of materiality and the definition of innovation. However, the relationship between $\mathrm{P}$ and $\mathrm{s}$ or $\mathrm{S}$ and sis not systemic. Indeed the service characteristics (s) are consubstantial to $\mathrm{P}$ and $\mathrm{S}$; these are not external components capable of creating a system.

The first of the above relationships $(\mathrm{P}+\mathrm{S})$ reflects what the literature on PSS (Tukker, 2004) calls 'Product-oriented PSS', while all the other relationships fall within the scope of the 'Useoriented PSS'.

\section{b)Product-oriented PSS: dematerialization and greening through the additionof services toproducts}

Product-oriented PSS are established by the addition of services to products. They may, however, take more or less sophisticatedand integrated forms, featuring more, or fewer, added services. Within this product-oriented PSS diversity, it is possible to distinguish two main sub-categories, according to the knowledge-intensity of added services.

\section{The addition of (relatively) lowknowledge-intensive services: services around the product}

The best-known form of product-oriented PSS is that which entails adding traditional services (generally those having (relatively) low knowledge-intensity) to a product. These PSS are similar to what Furrer $(1997,2010)$ calls "services around the product". Examples include the addition of different pre- and after- sales services, financial and insurance services, etc. which made Fordist economies so successful. Such PSS may be considered at micro level (the same company provides the combined supply of products and services) or at meso level (the joint offer is the result of a partnership between different actors). In the latter case, the PSS is more than just a design and product engineering concept since it also reflects a production and innovation network dimension.

It should be acknowledged that the originalpurpose of such a system is not ecological. By adding services to products, the objective pursued by companies is to gain a competitive advantage. Companies seek to improve the quality of goods, reduce costs, boost sales and thus increase profits. In some cases, the services added to the product can even be more profitable than the products themselves (Furrer 1997). By adding services to products, companies may also seek to lock down the relationship with the customer - in other words, to generate customer loyalty (Bryson 2010). The multiplication and tightening-upof service relationships (i.e. customer interaction)helpkeep the provider attentive to client needs, favouring adaption and innovation. It is now possible to state that the addition of services to products, and the concept of PSS, have enriched innovation theory, ahead of sustainable development theory. The two fields (innovation and sustainability) are now reconciledwithin this concept.

In this PSS approach, dematerialization arises out of multiple sources. First and foremost, it is mechanical (passive), a result of the rise of intangible services in the PSS. In other words, by adding services or service to products, the degree of immateriality of the entire PSSrises. In this way, the ratio between the 'volume' of material products and the 'volume' of intangible services serves an indicator of the degree of the service's materiality/immateriality. Within the supply of a given industrial firm, the volume of intangible services may increase,outweighing the volume of material products. This development, which raises sectoral allocation issues, is illustrated by the case of iconic industrial companies (particularly 
in IT) that have essentially become service providers. It should be noted that in this simple PSS approach, the reverse process of adding products to services also contributes to the creation of aPSS. Such a process, however, helps increase materiality, rather than reduce it.

Dematerialization is also active for some added services. This is, of course, the case of repair and maintenance services, as well as oftake-back and recycling services at the end of product life. All of these contribute to dematerialization through the expansion of the lifespan of either the products or some of their components, and by reducing use of virgin materials in the production process (Agri et al., 1999).

\section{The addition of KIBS: the P-KIBS System}

A product-oriented PSS can also be constitutedthrough the addition ofKnowledge-Intensive Business Services (KIBS) (various types of consultancy services, engineering, training, and research) to products (and services).The Product-KIBS system also contributes todematerialization of thesystem, in a mechanically (passive) way, by the simple juxtaposition of intangible services and physical products. This is not, however, the most important dematerialization/greening mechanism. Above all,KIBS contribute via an active role. Indeed, in this type of PSS, KIBS are primarily mobilized as agents of change. They can accompany and support the greening/dematerialization efforts of a business and corresponding innovations, whether technological or non-technological. A number of consulting companies have thus either specialized in providing greening services, orincluded this expertise in their service supply.

\section{c) Use-oriented PSS: dematerialization through the real or theoretical substitution of services for products}

The currently dominant PSS approachis broader than the previous one, since - beyond the systemic dimension (linking products and services), it is the distinction between products and services (and paradoxically between components of the system) that is called into question. Indeed, the main idea here is that, by nature, everything (including the product) is service and that material goods are subject to service uses. This PSSapproach is called 'Use-oriented PSS'.

- From the theoretical (and sometimes rhetorical) point of view, this PSS approachfalls within the scope of a perspective that reflects a radical change in perception of the nature of goods and services. In this vision"everything is service". Agricultural products, industrial products and services alike are of value only based on the service(s)or function(s)they provide.

- From the operational point of view, this PSS approach reflects, then, a change in the way products are used by consumers, associated with a change in the producer'sbusiness model. The company no longer providesproducts, and the consumer no longer acquires ownership of a product - rather, both respectively sell and buy the use of theproduct and the service it provides. From this perspective, products (such as cars, photocopiers, and machines)are no longer what are sold, but rather kilometres travelled, the number of photocopies made, hours of operation, and so on. This purchase of the service provided by the products can take many forms: renting and leasing (potentially even going as far asa 'pay per service unit' model $^{10}$ ), as well as sharing and pooling.

\footnotetext{
${ }^{10}$ An illustration is provided in the area of rental and leasing photocopiers.
} 
In this PSS approach, dematerialization and greening are not limited to the rise of mechanical immateriality through the addition of intangible services. Here the sources of immateriality and greening are more complex and difficult to grasp. They are linked to the decline in consumption of durable goods and the efforts made by producers to upgrade durable goods (sources of the services they sell) or extend their lifespan.

Though it reflects a blurring of the traditional analytical 'product and service' categories, PSS also questions (scrambles) our analytical categories in the field of innovation (whether or not related to sustainable development): its nature, its actors, its appropriation regime andits evaluation systems. In a PSS, therefore, innovation in products can come out of innovation in complementary services (this is well known in mature sectors, such as the automotive industry). Innovation takes systemic, architectural form. It concernsnot only products as such, but also their consumption or use modes. It also raises appropriation issues, given the multiplicity of stakeholders (and in particular the role of the user). It requires innovations in our innovation and performance measurement apparatus, in order to reflect - beyond industrial and technical performance - environmental and social performance (Hyytinen et al., 2015).

\section{Conclusion}

Insofar as it is through their material dimension that economic activities damage the environment, the alleged immateriality of services is often seen as a guarantee of their natural sustainability. Unlike goods for which the production process swallowsup exhaustible natural resources and harms the environment, services, by dint oftheir evanescent nature (long since emphasized by the founders of classical economics)are supposed to have a smaller environmental footprint.

In this work we have sought, firstly, to refute this myth of the immateriality of services. Even though a service outcome may be (or seem) immaterial, we must not forget the many materiality sources that the service conceals: materiality of the service medium, the production factors deployed andthe production/consumption spaces, as well as materiality relating to interactivity (which is integral to the previous two vectors of materiality).

Moreover, the materiality/immateriality of a service is not an objective, intrinsic, technical characteristic. It depends, firstly, onthe output convention adopted - that is, the scope agreed uponfor definition of the service, whether this is its topographical delimitation or its time horizon. Massive underestimation of service materiality often results from the exclusion (as often practiced by official statistics conventions) of certain components (such as travel)from the scope of a service. The materiality of the service is similarly underestimatedwhen it is limited to direct materiality, excluding indirect ('grey') materiality, which is 'incorporated' to buildings, furnishings, intermediate goods and technical systems in particular, as well as to intermediary services mobilized in the course of the service transaction. This service materiality also depends on the materialization/dematerialization strategies beingimplemented by service organizations.

Thus, whilethe service is not intrinsically intangible, innovation strategies can be implemented that will make it more or less material/immaterial. In this chapter, wehave only 
briefly touched on service materialization (industrialization)strategies in order to focus on dematerialization and greening strategies.

In their relationships to services, such dematerialization strategies can take two forms, each covering different sustainable innovation trajectories. The first of these internal dematerialization/greening approachesdescribes aset of innovation strategies entailingservices dematerializing and greening themselvesthrough actions designed toaffect the vectors of materiality:service mediums, production/consumption spaces, and production factors. The second form, known as an external materialization/greening strategy,encompasses a set of innovation strategies whichcomprise the dematerializing/greening of goods (and of the whole economy) through services and service innovation. The PSS concept occupies an important position in these dematerialization/greening strategies. It reflects(though sometimes ambiguously)various mechanisms: mechanical (passive) dematerialization via the simple association (juxtaposition) of goods and services; more complex dematerialization, based on a unified ontological conception of goods and services (everything is service) and on changing production and consumption patterns and ownership regimes, and dematerialization/greening though active KIBS intervention.

Overall, we can conclude that services are not by nature intangible and green, but that they are capable of dematerializing and greening themselvesvia the implementation of appropriate innovation strategies. This process of dematerialization and greening, supported by sustainable service innovation, must however be qualified by a number of remarks, some of which may be considered interesting avenues for a research agenda:

- In this work, we have focused on the dematerialization dynamics of services and of PSS. However, in contemporary economies, the two often go hand in hand with the contradictory dynamics of materialization. These are the two inseparable faces of Janus. Gallouj et al. (2015) describe the industrialization/servitization dialectic as one of the most powerful megatrends at work in contemporary economies. We might also askto what extent these two contradictory processes lead to a zero sum game in terms of materiality and sustainability.

- Analyses of dematerialization must take into account what is called the rebound effect. Indeed, the success of eco-friendly solutions can induce increased production and consumption, thus reducing the overall benefit.

- The two remarks above refer to the fundamental question of measurement systems. Most of our analyses remain theoretical or qualitative. The dematerialization issue raises formidable measurement problems. Thus, the idea of PSS sustainability - that is, theirless materialintensive nature (though considered acceptable in theory) is not validated by measurement. This is an important research issue. 


\section{References}

Agri J., Andersson E., Ashkin A., Söderström J. (1999), Selling services: a study of environmental and economic effects of selling functions. CPM report $\mathrm{n}^{\circ} 6$.

Baines T.S. et al. (2007), State-of-the-art in product service systems, Proceedings of the Institution of Mechanical Engineers, Part B: Journal of Engineering Manufacture, 221(10), p. 1543-52.

Barcet A. (1987), La montée des services: vers une économie de la servuction, PhD thesis, University Lyon-Lumière.

Baumol W.J. (1967), 'Macroeconomics of unbalanced growth', American Economic Review, 57 (2), 415-426.

Baumol W.J., Blackman S.A.B. and Wolff, E.N. (1985) "Unbalanced Growth Revisited: Asymptotic Stagnancy and New Evidence," American Economic Review, 75, September, p. 806-817

Bell D. (1973), The coming of post-industrial society, a venture in social forecasting, Basic Books, New York.

Berkhout F. Hertin J. (2001), 'Impacts of information and communication technologies on environmental sustainability: Speculations and evidence'. Report for OECD, SPRUScience and Technology Policy Research, University of Sussex.

Beuren F. H., Gomes Ferreira M. G., Cauchick Miguel P. A. (2013), 'Product-service systems: a literature review on integrated products and services', Journal of Cleaner Production, $\mathrm{n}^{\circ} 47$, p. 222-231.

Boutillier S., Laperche B., Picard F. (2014), Le développement des systèmes produits-services dans les entreprises: une étape vers l'économie de la fonctionnalité?Economies et Sociétés, Série EGS, $\mathrm{n}^{\circ} 15,4$, p. 551-578.

Bressand A. (1986), Europe in the new international division of labour in the field of services: the need for a new paradigm, report $n^{\circ} 2$ to the European Commission, PROMETHEE, Paris.

Bressand A., Distler C., Nicolaïdis K. (1989), Networks at the heart of the service economy, in Bressand A., Nicolaïdis K. (eds), Strategic trends in services: an inquiry in the global service economy, New York, Harper \& Row, p. 17-32.

Broussole D. (2015), La tertiarisation revisitée dans la perspective des services de Hill, un éclairage sur le cas de l'UE et de la France, Economies et Sociétés, série EGS, (forthcoming).

Bryson J. R., (2010), 'Service innovation and manufacturing innovation: bundling and blending services and products in hybrid production systems to produce hybrid products', in Gallouj F., Djellal F. (ed.), The Handbook of Innovation and Services. A Multi-Disciplinary Approach, Cheltenham, Edward Elgar, p. 679-721.

CEREN (21012), Suivi du parc et des consommations d'énergie du secteur tertiaire en 2010, Rapport technique.

Clark C. (1940), The conditions of progress and security, MacMillan, London.

Claval P. (2006), Le développement durable: stratégies descendantes et stratégies ascendantes, Géographie, Economie et Sociétés, Vol.8 (4), p. 415-445.

Cruz S., Paulino S., Paiva D. (2015), Service Innovation dynamics in solid waste sector: CDM landfill projects, XXV RESER conference "Service development and innovation for prosperity and human well-being in the 21 st century", Copenhagen, 1012 September.

De Vries E. (2006), 'Innovation in Services in Networks of Organizations and in the Distribution of Services', Research Policy, 35 (7), September, 1037-51 
Delaunay, J.C., Gadrey J. (1992), Services in Economic thought: three centuries of debate, Boston, Kluwer Academic Press.

Desmarchelier B., Djellal F., Gallouj F. (2011) Economic growth by waste generation: the dynamics of a vicious circle, Lecture Notes in Economics and Mathematical Systems, 652, p. 129-138.

Djellal F., Gallouj F. (2005), Mapping innovation dynamics in hospitals, Research Policy, Vol. 34, p. 817-835.

Djellal F., Gallouj F. (2010), Innovation in services and sustainable development, in P.P. Maglio, C.A. Kieliszewski, et J.C. Spohrer (ed), The Handbook of Service Science, Springer, 533-557.

Djellal F., Gallouj F. (2015), Green and sustainable innovation in a service economy, in Bryson J.R. and Daniels P. (eds) The Handbook of Service Business: Management, Marketing, Innovation and Internationalization, Edward Elgar Publishers, p. 535-559.

Djellal F., Gallouj F., (2008a), Measuring and improving productivity in services: issues, strategies and challenges, Edward Elgar Publishers.

Djellal F., Gallouj F., (2008b), A model for analysing the innovation dynamic in services: the case of 'assembled' services, International Journal of Services Technology and Management, Vol. 9, n 3/4, p. 285-304.

Du Tertre C. (2007), 'Économie de la fonctionnalité, développement durable et innovations institutionnelles', in Landrieu J., Heyrgon E. (éd.), L'économie des services pour le développement durable, Paris, L'Harmattan.

Eiglier P., Langeard E. (1987), Servuction. Le marketing des services, Paris, Ediscience international.

Ellger C., Scheiner J. (1997), After industrial society: service society as clean society? Environmental conséquences of increasing service intercation, Service Industries Journal, 17, p. 564-579.

Ettighoffer D. (1992), L'entreprise virtuelle. Ou les nouveaux modes de travail, Editions Odile Jacob, Paris.

Faucheux S., Hue C., Petit O. (2002). 'NTIC et environnement: enjeux, risques et opportunités', Futuribles, vol. 273, mars, p. 3-26

Foray D., Zuscovitch E. (1988), L'innovation entre la production et le système technique, in Arena et al. (eds), Traité d'économie industrielle, Economica, Paris, p. 602-615

Fourastié, J. (1949), Le grand espoir du XX siècle. Paris, Presse Universitaire de France.

Fourcroy C. (2015), Les innovations de services, une solution pour réduire les consommations d'énergie à l'hôpital? Innovation, les cahiers d'économie et de management de l'innovation (forthcoming).

Fourcroy C., Gallouj F., Decellas F. (2012), Energy consumption in service industries: challenging the myth of non-materiality, Ecological Economics, Vol. 81, September, p. $155-164$.

Fourcroy C., Gallouj F., Decellas F. (2015), "La matérialité invisible des services et ses implications énergétiques: une estimation de l'énergie brise par la méthode inputoutput", Revue d'économie industrielle, n 149 , 1 er trimester, p. 43-73.

Furrer O. (2010), 'A customer relationship typology of product services strategies', in Gallouj F., Djellal F. (ed.), The Handbook of Innovation and Services. A Multi-Disciplinary Approach, Cheltenham, Edward Elgar, p. 679-721.

Furrer, O. (1997), 'Le rôle stratégique des services autour de produits', Revue française de gestion, $\mathrm{n}^{\circ} 113$, p. 98-108.

Gadrey, J. (1991), 'Le service n'est pas un produit: quelques implications pour l'analyse économique et pour la gestion', in Politiques et Management Public, vol. 9, $\mathrm{n}^{\circ} 1$, mars, p. 1-24. 
Gadrey, J. (1996 a), Services: la productivité en question, Desclée de Brouwer.

Gadrey, J. (2000), The characterization of goods and services: an alternative approach, Review of Income and Wealth, 46(3), September, p. 369-387.

Gadrey, J. (2010), The environmental crisis and the economics of services: the need for révolution, inGallouj, F. and Djellal, F. (eds) (2010), The Handbook of Innovation and Services : a multidisciplinary perspective, Edward Elgar Publishers, p. 93-125.

Gallouj F., Djellal, F. (2015 forthcoming), Introduction: Services and innovation, inThe International Library of Critical Writings in Economics, Edward Elgar.

Gallouj, F. (2002), Innovation in services and the attendant old and new myths, Journal of socio-economics, Vol. 31, p. 137-154.

Gallouj, F. (2010), 'Services innovation: assimilation, differentiation, inversion and integration', in H. Bidgoli (ed.), The Handbook of Technology Management, Hoboken, NJ: John Wiley and Sons, pp. 989-1000

Gallouj, F., Toivonen, M. (2011), Elaborating the characteristics-based approach to service innovation: making the service process visible, Journal of Innovation Economics, 2011/2, n'8, p. 33-58.

Gallouj, F., Weinstein, O. (1997), Innovation in services, Research Policy, 26, p. 537-556.

Gershuny J. (1978), After industrial society? The emerging self-service economy, Mac Millan.

Goedkoop M.J., Van Halen C.J.G., te Riele H.R.M., Rommens, P.J.M. (1999), Product Service Systems, ecological and economic basis, Report for Dutch Ministries of Environment and Economic Affairs, Price Waterhouse Coopers.

Hill, P. (1977) 'On Goods and Services', the Review of Income and Wealth, 4-23, 315-338.

HyytinenK., RuutuS., Nieminen M., GalloujF., ToivonenM. (2015), A system dynamic and multi-criteria evaluation of innovations in environmental services, Economics and Policy of Energy and the Environment (fortcoming).

Hyytinen K., Toivonen M. (2015), Future energy services: empowering local communities and citizens, Foresight (special issue on services) (forthcoming).

Illeris S. (2007) "The nature of services", in Bryson John R., Daniels Peter W. (ed.) The handbook of service industries, Edward Elgar, Cambridge, p. 19-33.

International Energy Agency (2008), Worldwide trends in enrgy use and efficiency, key insights from IEA indicator analysis, in support of the G8 plan of action, OECD, IEA.

Kingman-Brundage, J. (1992), "The ABCs of Service System Blueprinting”, in Lovelock, C. (ed.), Managing services, Englewood Cliffs, New Jersey, Prentice-Hall International Editions, p. 96-102.

Levitt, T. (1972), "Production line approach to service", Harvard Business Review, 50, septembre-octobre, p. 41-52.

Lovelock, C., (1992) “A basic toolkit for service managers”, in Lovelock, C. (ed.), Managing services, Englewood Cliffs, New Jersey, Prentice-Hall International editions, p. 17-30.

Lusch, R., Vargo, S. (2006), Service-Dominant Logic: reactions, reflections and refinements, Marketing Theory, 6(3), 281-288.

Maglio P., Spohrer J. (2008), 'Fundamentals of Service Science', Journal of the Academy of Marketing Science, 36 (1), March, 18-20.

Manzini E., Vezzoli C., (2002), Product service-systems and sustainability: opportunities for sustainable solutions, United Nations Environment Programme (UNEP).

Manzini E., Vezzoli C., and Clark G. (2001), Product service-systems: using an existing concept as a new approach to sustainability, Journal of Design Research 1 (2).

Mont, O. (2002), 'Clarifying the concept of product-service system', Journal of Cleaner Production, vol. $10, \mathrm{n}^{\circ} 3$, p. 237-245. 
Neslon R., Winter S. (1982), An Evolutionary Theory of Economic Change, Belknap Harvard.

OECD (2000) The service economy, OECD Publications, Paris.

Ordanini A., Parasuraman (2011), Service innovation through a srvice-dominant logic lens: a conceptual Framework and empirical analysis, Journal of Service Research, 14, p. 323.

Pine, J. and Gilmore, J. (1999) The Experience Economy, Harvard Business School Press, Boston.

Rifkin J. (2000), L'âge de l'accès : la nouvelle culture du capitalisme, La découverte, Paris.

Romm J., Rosenfeld A., Herrman S. (1999), The Internet economy and global warming, The Center for Energy and Climate Solutions.

Say J.-B. (1972) (First édition 1803),Traité d'économie politique, Calmann-Levy, Paris.

Smith, A. (1960). (First Edition 1776) The Wealth of Nations, The Modern Library, Random House, New York.

Stahel, W. (1997). The Functional Economy: Cultural and Organizational Change, in Richards D.J. (ed) The industrial green game: implications for environmental design and management. Washington DC, National Academy Press, p. 91-100.

Storch H. (1823), Cours d'économie politique ou exposition des principes qui déterminent la prospérité des nations, Paris.

Tischner U., Verkuijl M., Tukker A. (2002) First Draft, PSS Review. SusProNet Report, draft 15 December. Available from Econcept, Cologne, Germany; TNO-STB.

Tukker A. (2004), Eight types of product-service system: eight ways of sustainability? experiences from SusProNet, Business Strategy and the Environment, 13, 246-260.

Vandermerwe, S. and Rada, J. (1988), 'Servitization of Business: Adding Value by Adding Services', European Management Journal, 6 (4), 314-24.

Vargo S.L., Wieland H., Archpru Akaka M. (2014), Innovation through institutionalization: A service ecosystems perspective, Industrial Marketing, Management, p. 63-72.

Windrum, P. and M. Garçia- Goñi, M. (2008), A neo-Schumpeterian model of health services innovation, Research Policy, 37 (4), 649-672. 